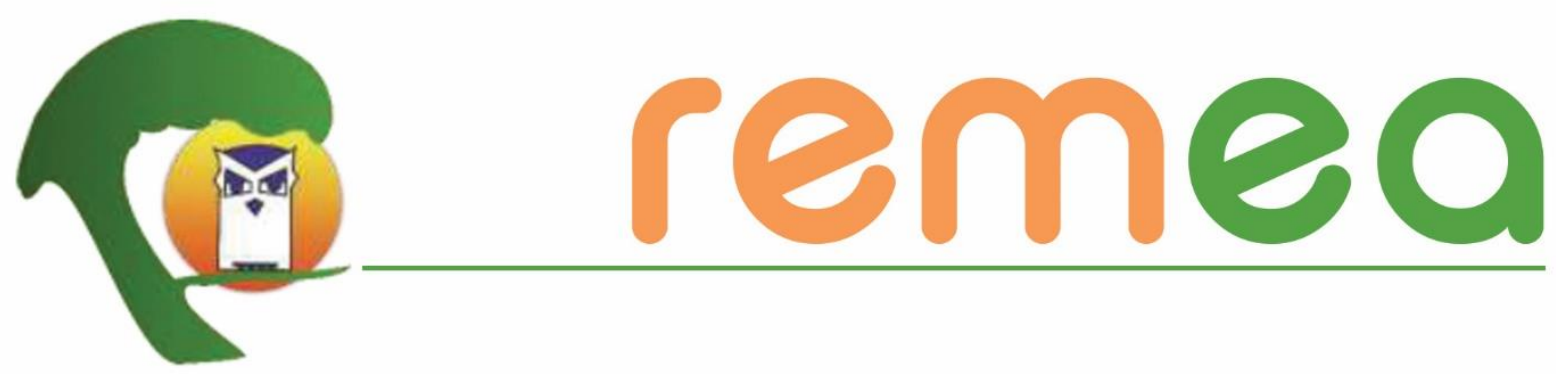

\title{
Análise da socialização das experiências do projeto Agente Mirim de Defesa Civil de Blumenau/SC por meio da educação ambiental
}

\author{
Jefferson Ribeiro ${ }^{1}$ \\ FURB- Fundação Universidade Regional de Blumenau \\ ORCID https://orcid.org/0000-0001-9463-1062 \\ Rafaela Vieira ${ }^{2}$ \\ FURB - Fundação Universidade Regional de Blumenau \\ ORCID https://orcid.org/0000-0001-6668-8758 \\ Luciana Schramm Correia ${ }^{3}$ \\ Prefeitura de Blumenau/SC \\ ORCID https://orcid.org/0000-0001-7117-2983
}

Resumo: As ações do projeto Agente Mirim de Defesa Civil (AMDC) realizado pela Defesa Civil (DC) de Blumenau, acontecem anualmente em escolas do município, promovendo o aprofundamento no tema Gestão de Risco de Desastres (GRD), envolvendo aulas teóricas e visitas de estudo. O objetivo da presente pesquisa foi identificar o grau de socialização das experiências dos estudantes sobre a GRD junto à sua família confrontando os dados obtidos com o conceito da Educação Ambiental (EA) Crítica-Transformadora. Como ferramenta metodológica, foram aplicados questionários com os responsáveis dos estudantes que participaram do projeto AMDC entre os anos de 2015 até 2018. A análise das respostas foi realizada pela técnica do Discurso do Sujeito Coletivo. Entre os resultados é possível confirmar que os responsáveis das três comunidades apresentam conhecimentos sobre a GRD, independente do ano em que foram aplicados os projetos. O pensamento CríticoTransformador utilizado pela DC durante suas práticas consolida a percepção dos riscos de desastres na comunidade.

Palavra-chaves: Educação Ambiental, Capacitação, Desastres Naturais.

\footnotetext{
${ }^{1}$ Biólogo e doutorando do Programa de Pós-graduação em Engenharia Ambiental da Universidade Regional de Blumenau (FURB). Blumenau (SC), Brasil. E-mail: jeff.r.bio@gmail.com

2 Doutora em Geografia pela UFSC. Docente do Programa de Pós-Graduação em Engenharia Ambiental da Fundação Universidade Regional de Blumenau (FURB). Blumenau (SC). E-mail: rafaela@furb.br

${ }^{3}$ Assistente Social e Coordenadora do Projeto Defesa Civil na Escola na Secretaria Municipal de Defesa Civil de Blumenau. Blumenau (SC). E-mail: lucianacorreia@blumenau.sc.gov.br
}

Revista Eletrônica do Mestrado em Educação Ambiental Programa de Pós-Graduação em Educação Ambiental - FURG v. 38, n. 1, p. 178-201, jan./abr. 2021. E-ISSN: 1517-1256 


\title{
Análisis de la socialización de las experiencias del Proyecto de Defensa Civil Mirim en Blumenau / SC a través de educación ambiental
}

Resumen: Las acciones del proyecto Agente Civil de Defensa de la Niñez (ACDN) que lleva a cabo la Defensa Civil (DC) de Blumenau, se desarrollan anualmente en las escuelas del municipio, promoviendo la profundización en la temática de Gestión del Riesgo de Desastres (GRD), involucrando clases teóricas y visitas de estudio. El objetivo de esta investigación fue identificar el grado de socialización de las experiencias de los estudiantes sobre la GRD con su familia, confrontando los datos obtenidos con el concepto de Educación Ambiental Crítico-Transformativa (EA). Como herramienta metodológica, se aplicaron cuestionarios con los tutores de los estudiantes que participaron en el proyecto ACDN entre los años 2015 a 2018 . El análisis de las respuestas se realizó mediante la técnica del Discurso Colectivo del Sujeto. Entre los resultados, es posible constatar que los jefes de las tres comunidades tienen conocimiento sobre GRD, independientemente del año en que se aplicaron los proyectos. El pensamiento Crítico-Transformador utilizado por DC durante sus prácticas consolida la percepción de los riesgos de desastres en la comunidad.

Palabras-clave: Educación Ambiental, Entrenamiento, Desastres naturales.

\section{Analysis about socialization of experiences in Junior Civil Defense Agent project at Blumenau / SC through environmental education}

\begin{abstract}
The actions of the Junior Civil Defense Agent (JCDA) project carried out by the Civil Defense (CD) of Blumenau, take place annually in schools in the city, promoting the deepening in the theme of Disaster Risk Management (DRM), involving theoretical classes and study visits. The aim of this research was to identify the degree of socialization of students' experiences about DRM with their family, confronting the data obtained with the concept of Critical-Transformative Environmental Education (EE). As a methodological tool, questionnaires were applied with the responsible of the students who participated in the JCDA project between the years 2015 to 2018. The analysis of the responses was carried out using the Collective Subject Discourse technique. Among the results, it is possible to confirm that the heads of the three communities have knowledge about DRM, regardless of the year in which the projects were applied. The Critical-Transformative thinking used by $C D$ during its practices consolidates the perception of disaster risks in the community.
\end{abstract}

Keywords: Environmental Education, Training, Natural disasters.

\section{Capacitações de estudantes para o enfrentamento de desastres em Blumenau}

O município de Blumenau localizado na Bacia Hidrográfica do rio Itajaí (BHRI), no estado de Santa Catarina apresenta um extenso histórico de desastres naturais. Em 2008 a BHRI foi assolada por enxurradas, inundação e movimentos de massas que transformaram a localidade em um campo de guerra (AVILA; MATTEDI, 2017).

A presença de precipitação intensa em curta escala de tempo causou impactos severos na economia da região. As perdas foram inúmeras, abrangendo também as áreas ambientais e sociais. Portanto, para a BHRI esse evento é considerado um marco histórico. Após sua passagem os gestores tiveram que modificar suas estratégias na gestão dos riscos 
de desastres. Por consequência, muitas alternativas foram repensadas na busca de minimizar os efeitos e promover resiliência no município.

De acordo com Oliveira, Ouriques e Correia (2018) como forma de minimizar os impactos dos desastres e considerando a inexistência de um programa com ações para Gestão de Riscos de Desastres (GRD), foi introduzido em Blumenau, através da Diretoria de Defesa Civil, práticas educativas em escolas da rede pública e particular que promovessem a prevenção e potencializassem uma mudança cultural de proteção individual e coletiva em situações de desastres.

Assim, desde o ano de 2014 a Defesa Civil (DC) vem promovendo no município dois projetos: o Defesa Civil na Escola (DCE) e o Agente Mirim de Defesa Civil (AMDC). O DCE capacita anualmente, por meio de três encontros os alunos dos 50 anos de 10 escolas municipais. Nestes encontros são abordados conteúdos sobre noções básicas de defesa civil. Já o projeto AMDC envolve anualmente 30 crianças por meio de aulas teóricas quinzenais em salas de aula e atividades práticas com visitas educativas. Esse projeto acontece anualmente em uma escola de Blumenau que já tenha participado do projeto DCE (VIEIRA; RIBEIRO, 2018).

Por meio de aproximadamente 16 encontros, os estudantes obtém a oportunidade de conhecer o 23으 Batalhão de Infantaria, áreas de risco com auxílio de técnicos, aulas de primeiros socorros, Educação Ambiental (EA) em parque florestal, visitas à estação de tratamento de esgoto além de outras atividades (VIEIRA; RIBEIRO, 2018). Até o ano de 2019, várias unidades escolares já foram contempladas (Figura 1).

Vale destacar que nos diferentes anos de desenvolvimento do projeto AMDC houve algumas particularidades entre as diferentes turmas (Quadro 1), relacionadas ao ano escolar, número de estudantes, tipologias de riscos de desastres próximos a escola, diferença dos turnos de realização dos encontros, visando melhor adaptação à realidade dos ambientes escolares participantes (Quadro 1). 
Figura 1: Localização das unidades escolares e seu respectivo grupo de estudantes. Obs: As letras F, G e H correspondem ao grupo formado por 90 alunos participantes das três escolas de 2019

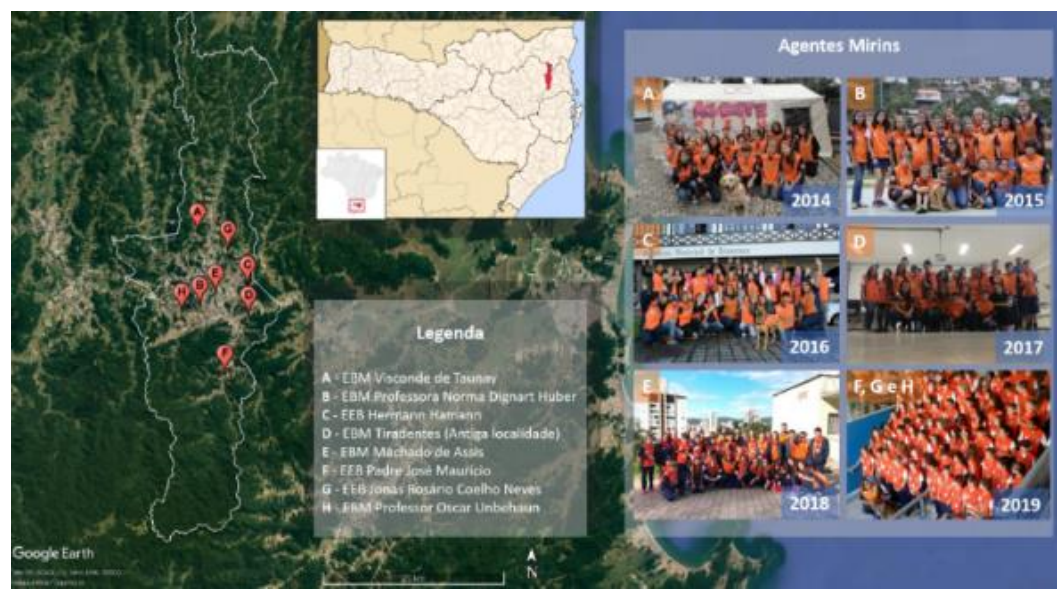

Fontes: Imagem de satélite - BLUMENAU (2020), Mapa de Santa Catarina - LOCALIZAÇÃO (2006) e fotos Prefeitura de Blumenau

O projeto AMDC contou, ao longo dos anos, com uma parceria com a universidade local, cujos projetos de pesquisa e extensão apresentaram contribuições para seu aprimoramento, por meio da inserção de ferramentas tecnológicas, ao incorporar animações e documentários nas atividades, assim como proporcionar a participação dos estudantes em atividades desenvolvidas no laboratório de Tecnologia da Informação e Comunicação (TIC).

Frente a esse contexto o problema de pesquisa que se expressa é: se existe e como se apresenta o grau de socialização junto à família, das experiências que os estudantes vivenciaram no projeto AMDC sobre a GRD, confrontando-se os dados obtidos com o conceito da Educação Ambiental (EA) Crítica-Transformadora.

Quadro 1: Caracterização das turmas que participaram do projeto AMDC até 2019

\begin{tabular}{|l|l|l|l|l|l|}
\hline Ano & Escola & Turma & $\begin{array}{l}\text { № de } \\
\text { estudantes }\end{array}$ & $\begin{array}{l}\text { Tipologias de riscos de } \\
\text { desastres próximos da escola }\end{array}$ & $\begin{array}{l}\text { Horário dos } \\
\text { encontros }\end{array}$ \\
\hline 2014 & EBM Visconde De Taunay & 60 ao 9o ano & 20 & Deslizamentos e inundações & Contraturno \\
\hline 2015 & EBM Norma Dignart Huber & 60 ano & 20 & Deslizamento & Contraturno \\
\hline 2016 & EEB Hermann Hamann & 70 ano & 26 & Deslizamento & Turno \\
\hline 2017 & EBM Tiradentes & 60 ano & 21 & Deslizamento & Turno \\
\hline 2018 & EBM Machado de Assis & 60 ano & 33 & Deslizamentos e inundações & Turno \\
\hline 2019 & EEB Padre José Maurício & 60 ano & 30 & Deslizamentos & Contraturno \\
\hline 2019 & EEB Jonas Rosário Coelho Neves & 60 ano & 30 & Deslizamentos e inundações & Contraturno \\
\hline 2019 & EBM Professor Oscar Unbehaun & 60 ano & 30 & Enxurradas & Contraturno \\
\hline
\end{tabular}

Legenda: \begin{tabular}{|l|l|l|l|l|l|}
\hline & Projeto piloto & EBM & Escola Básica Municipal & EEB & Escola de Educação Básica \\
\hline
\end{tabular}

Fonte: Os autores (2019) 
A EA Crítica-Transformadora dentro da perspectiva da capacitação em GRD

De acordo com UNISDR (2015) é previsto no marco de Sendai a importância de promover a geração de conhecimento para os processos de prevenção, mitigação, preparação, resposta, recuperação e reabilitação que caracterizam a GRD, tendo-se as práticas educativas como fio condutor. Existe também a relevância de desenvolver estratégias nacionais, as quais proporcionem reforçar a educação e a sensibilização pública sobre a gestão do risco de desastres. Além dessas propostas para a capacitação da população, abordar conhecimentos sobre GRD nas escolas é algo pertinente, pois é por meio dessas informações que se torna possível construir cidades resilientes aos impactos causados pela passagem de eventos naturais em áreas vulneráveis.

Neste sentido o United Nations International Strategy for Disaster Reduction (UNISDR), com base no Marco de Ação de Hyogo, cujo período de vigência foi 2005-2015, apresentou a campanha: Construindo Cidades Resilientes. Esta campanha trouxe um modelo para consolidar a resiliência nos sistemas urbanos por meio de dez passos, os quais incorporam as atividades críticas e interdependentes, visando o cumprimento pelos poderes públicos locais (ONU, 2012).

Dando sequência aos avanços sobre a temática GRD, no ano de 2016, em evento realizado em Florença, discutiu-se a atualização da Campanha Construindo Cidades Resilientes, com base no Marco de Ação de Sendai, estabelecido para 2015-2030 (UNISDR, 2015). Por meio de novos avanços obtidos durante esses eventos, no ano de 2017 a UNISDR publicou o documento: Como desenvolver cidades mais resilientes, sendo este um manual desenvolvido para líderes de governos locais.

De acordo com UNISDR (2017) para reduzir o risco de desastres é possível utilizar uma abordagem sistemática, proativa e multifacetada, sendo necessária para definir, avaliar e desenvolver planos que possibilitem reduzir os riscos de desastres.

No âmbito nacional a relevância da presença destes conhecimentos na escola, são apresentados por diferentes estudos. No Brasil, pesquisas no campo socioambiental demonstram que a educação ambiental pode contribuir para a gestão de riscos de desastres por conseguir colaborar no desenvolvimento da construção da cidadania através da 
compreensão da situação de risco, por exemplo, pelas populações que vivem em áreas vulneráveis (ROSA et al., 2015).

Contudo, o enfrentamento dessa situação requer a construção de uma percepção e compreensão do mundo que contemple a complexidade que o caracteriza. A Educação Ambiental, nessa perspectiva, tem como objetivo a formação e o desenvolvimento individual de atitudes éticas e a aquisição de valores em relação à natureza que conduzirão a mudanças de comportamento (LORENZETTI, 2008).

Conforme descrito anteriormente, todos os anos nas escolas de Blumenau são realizadas capacitações. Essas formações tem como objetivo principal desenvolver nos estudantes a percepção dos riscos de desastres, fazendo com que os participantes consigam observar os elementos chaves que potencializam a consolidação dos riscos na sua localidade, bem como, informar aos demais membros da sua comunidade como se proteger destes eventos. Portanto, esta pesquisa procura compreender, como a educação ambiental em sua vertente Crítica-Transformadora pode potencializar as práticas da Defesa Civil para a construção desta percepção.

De acordo com Torres (2010) a EA crítica é fundamentada dentro dos princípios da teoria crítica do conhecimento, que apresenta na educação bases e princípios voltados ao diálogo, compreensão do mundo ao averiguar toda sua complexidade, cidadania, entre outros temas que possibilitam a EA ser considerada como um elemento de transformação social do indivíduo.

Para Layrargues e Lima (2014) EA representada em sua macrotendência crítica, a possibilidade de trabalhar a emancipação do estudante, fator que auxiliar o educando no processo de gestão ambiental. Além disso, apresenta ênfase na revisão dos fundamentos que proporcionam buscar o enfrentamento político das desigualdades e da injustiça socioambiental. Em um mundo capitalista, essas desigualdades, tendem a promover a potencialização dos eventos de desastres socioambientais.

Uma alternativa para isso vincula-se na abordagem da educação ambiental crítica que de acordo com Tavolaro (2005, p.21):

[...] aponta para a construção de uma sociedade democrática cujas instituições, processos e âmbitos de formação da vontade política e de tomada de decisões sejam consistentemente permeáveis à participação de cidadãos livres e 
autônomos, a despeito da crescente complexidade e diferenciação característica das modernas sociedades.

Vale enfatizar que conforme evidenciado por Layrargues e Lima (2014) existem na educação ambiental outras duas macrotendências que são comuns dentro da prática educativa, sendo a conservacionista e a pragmática. A conservacionista percebe o meio ambiente destituído de componentes humanos, tendo escopo basicamente a ecologia. $\mathrm{A}$ pragmática apresenta pouco embasamento no potencial crítico da articulação das dimensões sociais, culturais, econômicas, políticas e ecológicas (LAYRARGUES; LIMA, 2014). Por esses motivos, para o ensino da GRD não são indicadas abordar essas macrotendências, pois os estudantes não constroem conhecimentos necessários para perceber a ligação existente entre a sociedade e o ambiente e observar que as vulnerabilidades estão associadas a exposição humana a espaços com características que não condizem com o desenvolvimento das populações, aumentando consideravelmente os riscos de desastres.

Desta forma, esta pesquisa procura debater a importância que a EA crítica apresenta para a consolidação da percepção dos riscos de desastres. De acordo com Tavolaro (2005), nesta vertente a EA é considerada como transformadora e libertária ao possibilitar envolver qualquer tipo de questionamento conectado as ações humanas, bem como englobar as esferas sociais, econômicas, políticas e culturais ao invés de apenas legitimá-las. Assim a EA apresenta questionamentos para serem debatidos a respeito das condições que interferem diretamente na qualidade de vida da população.

Portanto, sua inclusão em capacitações é primordial para que os discentes entendam os diferentes processos que atuam ativamente no meio ambiente, como um mecanismo complexo e integrado, ou seja, saber que cada um desses fatores são engrenagens com valores e papeis díspares, estando relacionadas diretamente na manutenção para promoção da qualidade da vida dos seres vivos. Por isso, é relevante que a mediação de conceitos de desastres englobe uma visão ampla, saindo da exclusividade do pensamento ecológico, mas englobando meios que não podem ser desvalorizados, especialmente quando estamos falando sobre gestão de riscos de desastres.

Conforme abordado por Lorenzetti (2008) o pensamento Crítico-Transformador traz essa bagagem, pois explora o ambiente por meio da visão sistêmica, envolvendo diversas 
dimensões que vão além dos aspectos naturais, como por exemplo, as questões históricas, e políticas.

Além disso, "numa perspectiva crítica, o principal indicador de sucesso de uma ação educativa ambiental está não no alcançar metas previamente definidas, mas em se estabelecer um processo de aprendizagem que seja participativo, emancipatório e transformador" (LOUREIRO, 2005, p. 328).

Por isso o mediador, no aspecto da capacitação em GRD, deve em suas práticas aplicar atividades que busquem emancipar o estudante, transformando os mesmos em participantes ativos ao abordarem os conhecimentos adquiridos com sua comunidade. Assim, ressalva-se que o mediador deve avaliar as diferentes dimensões, não se limitando apenas no aspecto natural, pois ao ficar restritos a este caráter propicia-se de desenvolver uma visão extremamente fragmentada de mundo, o que dificulta a compreensão das interações que os seres humanos mantêm com tudo que o cerca (LORENZETTI, 2008).

Nesse sentido ao abordar os princípios da GRD, tais como os processos de prevenção, mitigação, preparação, resposta, recuperação e a geração de conhecimento apresentado por Narváez, Lavell e Ortega (2009) o mediador deve utilizar uma metodologia que promova com que o estudante compreenda seu papel dentro do ambiente. Podendo seguir os princípios da concepção educacional freireana.

Segundo Torres (2010) essa concepção abordada por Paulo Freire é construída em fundamentos baseados nas categorias da problematização, do diálogo e da conscientização, as quais uma vez inseridas aos temas abordados pelos mediadores proporcionam a consolidação de uma educação emancipatória e democrática, construindo no estudante capacidades que possibilitam desenvolver sua participação responsável nos principais processos relacionados a conexão sustentável entre os seres humanos e o ambiente.

Portanto, sabendo da importância que o projeto AMDC desenvolvido pela DC pode promover junto à comunidade escolar e da relevância que a EA tem na capacitação de estudantes no enfrentamento de desastre, busca-se com esta pesquisa, realizada em parceria com o órgão da DC, identificar o grau de socialização das experiências assimiladas e multiplicadas pelos agentes mirins junto à sua família, confrontando os resultados deste estudo com o conceito da EA Crítica-Transformadora para a capacitação em GRD. 


\section{Percurso Metodológico}

A pesquisa foi realizada durante o ano de 2018 em três escolas das cinco que já participaram do projeto. As unidades escolares selecionadas foram (1) EBM Professora Norma Hubert, 2015, (2) EEB Hermann Hamann, 2016 e (3) EBM Machado de Assis, 2018 (Figura 1). As outras duas escolas respectivas aos anos de 2014 e 2017 não foram selecionadas, devido o prazo de aplicação do projeto, bem como por uma das unidades escolares ter sido novamente realocada de localidade. Com isso, muitos alunos não estudam mais nas unidades o que dificultava localizar os responsáveis legais.

Um desenho do percurso metodológico é apresentado no fluxograma (Figura 2). A primeira etapa da pesquisa aborda os locais e os envolvidos no estudo. Na segunda etapa é exposta a ferramenta de coleta e o método de obtenção dos dados. A terceira e última etapa trata-se da forma de análise dos dados.

Este estudo foi aprovado pelo comitê de ética sob o CAAE no 02108818.2.0000.5370. Os objetivos da pesquisa foram apresentados aos participantes, por meio do Termo de Consentimento Livre e Esclarecido (TCLE), sendo a participação voluntária, com liberdade de desistência do estudo a qualquer momento. No documento que apresentou o questionário estava impresso um QRCode seguido de um link que direcionava a um vídeo, no qual o pesquisador detalhava como a pesquisa seria conduzida.

Figura 2: Percurso metodológico aplicado na pesquisa

\begin{tabular}{|c|c|c|c|}
\hline \multicolumn{4}{|c|}{ AVALIAÇÃO DO PROJETO AGENTE MIRIM DE DEFESA CIVIL A PARTIR DA ÓTICA DOS PAIS } \\
\hline \multirow{2}{*}{$\begin{array}{c}1 \mathfrak{a} \\
\text { Etapa }\end{array}$} & Local & $\begin{array}{l}\text { Três (3) escolas de } \\
\text { Blumenau }\end{array}$ & Unidades que participaram do AMDC \\
\hline & Estudante & $\begin{array}{l}\text { Ex-estudante Participante } \\
\text { AMDC }\end{array}$ & $\begin{array}{l}79 \text { participantes entre os anos de } 2015 \text { até } \\
2018\end{array}$ \\
\hline \multirow{4}{*}{$\begin{array}{c}2 \mathrm{a} \\
\text { Etapa }\end{array}$} & Ferramenta & \multirow{2}{*}{ Entrega de questionário } & $\begin{array}{l}\text { Composto por seis (6) perguntas e documento com } \\
\text { instruções que esclarecem a pesquisa. }\end{array}$ \\
\hline & & & $\begin{array}{l}\text { Entregue a todos os estudantes que ainda } \\
\text { frequentam a unidade escolar }\end{array}$ \\
\hline & Coleta de Dados & Na casa dos estudantes & Responsáveis legais vão responder o \\
\hline & $\begin{array}{l}\text { Recebimento e envio de } \\
\text { informações }\end{array}$ & $\begin{array}{l}\text { Devolução do } \\
\text { questionário }\end{array}$ & Recolhido pelo pesquisador na escola \\
\hline $\begin{array}{c}\text { 3a } \\
\text { Etapa }\end{array}$ & Análise & Uso da Técnica DSC & Construção do DSC \\
\hline
\end{tabular}

Fonte: Os autores (2019) 


\section{Aplicação do questionário}

Para identificar e analisar qual o conhecimento de GRD permanece na percepção dos estudantes após sua vivência junto as ações do projeto AMDC e como eles são repassados a sua comunidade, em especial a sua família, foram aplicados questionários a um dos responsáveis legais dos estudantes. Portanto, para realizar tal procedimento foram enviados documentos com informativos da pesquisa, bem como o questionário que é apresentado no quadro 2. Desta forma um representante da Defesa Civil de Blumenau junto com um pesquisador, se deslocaram até as escolas para encaminhar 69 questionários aos responsáveis dos estudantes que participaram das ações do projeto em 2015, 2016 e 2018. A pesquisa foi estruturada em seis perguntas.

Quadro 2: Perguntas a serem respondidas pelos responsáveis legais

\begin{tabular}{|l|l|}
\hline \multicolumn{1}{|c|}{ Perguntas } \\
\hline $\begin{array}{l}\text { (1) Seu filho(a), compartilhou alguma informação sobre o que } \\
\text { aprendeu no Projeto? }\end{array}$ & $\begin{array}{l}\text { Verificar se as informações repassadas pelo projeto são } \\
\text { compartilhadas com seus familiares. }\end{array}$ \\
\hline $\begin{array}{l}\text { (2) Você aprendeu alguma coisa que não sabia, através do seu } \\
\text { filho(a)? }\end{array}$ & $\begin{array}{l}\text { Verificar o potencial de capacitação desenvolvido pelo estudante } \\
\text { após participar do projeto. }\end{array}$ \\
\hline $\begin{array}{l}\text { (3) Você percebeu no Agente Mirim mudança no seu } \\
\text { comportamento ou em suas práticas diárias a partir da sua } \\
\text { participação no Projeto Agente Mirim de Defesa Civil? }\end{array}$ & $\begin{array}{l}\text { Analisar se o estudante modificou o comportamento após vivenciar } \\
\text { o projeto AMDC. }\end{array}$ \\
\hline (4) Você observou nele um novo "olhar" para a sua comunidade. & $\begin{array}{l}\text { Verificar se o estudante começou a demonstrar maior interesse por } \\
\text { sua comunidade em relação aos riscos de desastres. }\end{array}$ \\
\hline $\begin{array}{l}\text { (5) Qual a sua opinião sobre o projeto de prevenção nas escolas? } \\
\text { Averiguar a opinião dos responsáveis legais sobre a aplicação do } \\
\text { projeto AMDC nas escolas de Blumenau. }\end{array}$ \\
\hline $\begin{array}{l}\text { (6) Caso desejares, comente suas considerações, sugestões ou } \\
\text { reclamações sobre o projeto Agente Mirim de Defesa Civil? }\end{array}$ & $\begin{array}{l}\text { Obter novas informações que possam enriquecer o trabalho } \\
\text { desenvolvido pelos agentes da Defesa Civil no projeto AMDC e } \\
\text { repassar essas informações ao órgão. }\end{array}$ \\
\hline
\end{tabular}

Fonte: Defesa Civil de Blumenau e autores (2019)

\section{Análise das respostas}

A transcrição e tabulação das respostas descritivas das entrevistas foram analisadas pela Técnica do Discurso do Sujeito Coletivo (DSC) proposta por Lefèvre e Lefèvre (2005). O discurso trata-se de um método para organização e tabulação dos dados qualitativos, obtidos dos depoimentos, embasando-se no fundamento da teoria da representação social (Figura 3).

A proposta do DSC incide na análise do material coletado, obtido de cada um dos participantes envolvidos (LEFÈVRE; CRESTANA; CORNETTA, 2003). Utilizando esta técnica, a 
metodologia funciona de acordo com a figura 3. Desta forma, temos as seguintes estruturas: Expressões-chave $(E C)$, são trechos ou transcrições literais obtidas do discurso do entrevistado, abordando a essência do depoimento. As expressões são posteriormente distribuídas em categorias diversas, definidas como "Ideias-Centrais" (IC), que sintetizam a ideia de cada grupo de discursos, sendo assim, revela e descreve fidedignamente o sentido de cada um dos discursos analisados, assim como, cada conjunto similar de EC, que possibilitará originar posteriormente o DSC (CAVALCANTI et al., 2010; LEFÈVRE; LEFÈVRE, 2005).

Figura 3: Etapas para elaboração do DSC

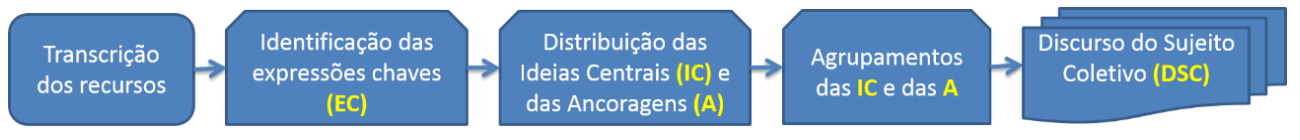

Fonte: Cavalcanti et al. (2010) adaptado pelos autores

Concluídas as etapas anteriores as ECs são agrupadas pelas categorias definidas nos ICs, proporcionando assim, um discurso que reproduzirá a fala de um sujeito coletivo, isto é, promover o Discurso do Sujeito Coletivo (DSC). Portanto o DSC é considerado como uma estratégia metodológica que busca tornar mais evidente uma dada representação social (CAVALCANTI et al., 2010; LEFÈVRE; LEFÈVRE, 2005).

\section{Resultados e discussão}

Das três escolas selecionadas para participar da presente pesquisa o percentual médio de retorno das entrevistas foi de $34,78 \%$ conforme observado no quadro 3 . Possivelmente, por ter maior quantidade de estudantes inseridos no projeto e também ter recebido o questionário no final da sua participação no AMDC em 2018 a escola Machado de Assis apresentou a maior devolutiva de questionários.

Quadro 3: Quantidade de questionários entregues e recebidos

\begin{tabular}{|c|c|c|c|c|c|c|}
\hline Unidade escolar & $\begin{array}{c}\text { Ano de participação } \\
\text { no projeto }\end{array}$ & Alunos & $\begin{array}{c}\text { Questionários } \\
\text { entregues a alunos } \\
\text { presentes }\end{array}$ & $\begin{array}{l}\text { Questionários } \\
\text { respondidos }\end{array}$ & \multicolumn{2}{|c|}{ Percentual } \\
\hline Norma Dignart Huber & 2015 & 20 & 18 & 6 & \multicolumn{2}{|l|}{$33,3 \%$} \\
\hline Machado de Assis & 2018 & 33 & 33 & 14 & \multicolumn{2}{|l|}{$42,42 \%$} \\
\hline Total & & 79 & 69 & 24 & Média & $34,78 \%$ \\
\hline
\end{tabular}

Fonte: Os autores (2019) 
Em relação ao primeiro questionamento que procurou observar se o estudante compartilhou alguma informação do que aprendeu no projeto, é possível verificar por meio da técnica do DSC que nas três comunidades escolares foi recorrente as informações de não morar em áreas de risco, dos conhecimentos sobre como agir antes, durante e após um desastre, da importância de alertar a população sobre estes eventos, da relevância em escolher espécies vegetais adequadas para evitar os desastres, das técnicas de primeiros socorros, da gestão adequada do lixo e da importância da escola como abrigo (Quadro 4). Averiguando estes sete discursos é possível confirmar que os alunos compartilharam informações relevantes para a gestão de risco de desastres com seus familiares. $\mathrm{O}$ aspecto da percepção de risco foi o mais abrangente nas respostas. Cabe aqui destacar, que este também é um dos conteúdos mais enfatizado pelos técnicos da DC durante a capacitação dos envolvidos no projeto AMDC.

Quadro 4: Seu filho(a), compartilhou informações sobre o que aprendeu no Projeto?

\begin{tabular}{|c|c|}
\hline Ideia Central - 1 & Discurso do sujeito Coletivo - 1 \\
\hline $\begin{array}{l}\text { Não morar em áreas de } \\
\text { risco e antes de } \\
\text { construir comunicar a } \\
\text { Defesa Civil }\end{array}$ & $\begin{array}{l}\text { Falou sobre locais considerados como perigosos, áreas de risco, das enchentes e deslizamento. Afirmou sobre } \\
\text { não morar nessas áreas e sim realizar construções em local seguro. Falou sobre os perigos de construir em } \\
\text { áreas de invasões. De não poder construir casas em barrancos. Comentou que antes de construir deve-se } \\
\text { consultar ou chamar a Defesa Civil para ver se pode. Reforçou que é possível identificar abalos na estrutura do } \\
\text { imóvel pelos trincos, que identificam possíveis áreas de risco. Assim a orientação é de desocupar as áreas de } \\
\text { risco, quando necessário, e se dirigir para o abrigo mais próximo. }\end{array}$ \\
\hline Ideia Central - 2 & Discurso do sujeito Coletivo - 2 \\
\hline $\begin{array}{l}\text { Como se prevenir e agir } \\
\text { antes e durante um } \\
\text { desastre }\end{array}$ & $\begin{array}{l}\text { Informou sobre a importância de cuidar da natureza. Como se prevenir de enchentes, principalmente de } \\
\text { deslizamentos e sobre o salvamento de pessoas. Também comentou sobre como agir antes, na hora do } \\
\text { desastre, e depois do acontecimento. Reforçou sobre os cuidados com dias consecutivos de chuva, pois quando } \\
\text { chove muito deve-se ter o cuidado com deslizamentos, enchentes e outros eventos. Informou que havia } \\
\text { apreendido, a importância de preservar a natureza para evitar os desastres naturais e os problemas nas áreas } \\
\text { de risco. }\end{array}$ \\
\hline Ideia Central - 3 & Discurso do sujeito - 3 \\
\hline $\begin{array}{l}\text { Comunicar a população } \\
\text { sobre riscos de } \\
\text { desastres }\end{array}$ & $\begin{array}{l}\text { Devemos ajudar a comunidade como um todo. O estudante comentou que aprendeu como lidar quando ocorre } \\
\text { um desastre e como alertar as pessoas. É importante informar a população sobre os desastres naturais. Em } \\
\text { uma tragédia os órgãos se unem para ajudar quem precisa. Uma forma importante é a comunicação via rádio. } \\
\text { O estudante aprendeu a usar rádio amador. }\end{array}$ \\
\hline Ideia Central - 4 & Discurso do sujeito Coletivo - 4 \\
\hline $\begin{array}{l}\text { A importância da } \\
\text { vegetação adequada } \\
\text { para evitar os desastres }\end{array}$ & $\begin{array}{l}\text { Compartilhou que não podemos plantar bananeiras em morros e nem pr } \\
\text { as árvores (sua inclinação) durante as chuvas, ter calhas na casa. Informo } \\
\text { sobre o solo e sobre a água parada e reforçou principalmente sobre o des }\end{array}$ \\
\hline Ideia Central - 5 & Discurso do sujeito Coletivo - 5 \\
\hline $\begin{array}{l}\text { A importância das } \\
\text { técnicas sobre primeiros } \\
\text { socorros }\end{array}$ & $\begin{array}{l}\text { Sim, compartilhou sobre as técnicas de primeiros socorros, informando como proceder e comentando sobre a } \\
\text { imobilização. }\end{array}$ \\
\hline Ideia Central - 6 & Discurso do sujeito Coletivo - 6 \\
\hline $\begin{array}{l}\text { A gestão adequada de } \\
\text { lixo }\end{array}$ & $\begin{array}{l}\text { Não jogar o lixo em local incorreto. Pois não devemos jogar no chão, na rua e rios a fim de evitar o } \\
\text { entupimento dos bueiros. Informou sobre o armazenamento e descarte correto de lixo. }\end{array}$ \\
\hline Ideia Central - 7 & Discurso do sujeito Coletivo - 7 \\
\hline $\begin{array}{l}\text { A importância da escola } \\
\text { como um abrigo }\end{array}$ & $\begin{array}{l}\text { Confirmou que a escola serve de abrigo. Que devemos levar de nossa casa só o necessário. E se por acaso } \\
\text { acontecer alguma coisa com sua casa a pessoa deve encaminhar-se para o abrigo mais próximo. }\end{array}$ \\
\hline
\end{tabular}
Fonte: Os autores (2019)

Observando com detalhamento os discursos é possível verificar que os estudantes desenvolveram uma visão crítica em relação aos aspectos ambientais e sua dinâmica com os 
desastres. Essa informação reforça que os técnicos da DC não fazem uso exclusivo do pensamento ecológico como a única forma de trabalhar educação ambiental nas escolas. De acordo com Lorenzetti (2008) entre suas principais características o pensamento ecológico aborda a preocupação com a destruição dos recursos naturais, focando basicamente na visão da conservação e preservação do ambiente natural.

Pelas respostas obtidas no DSC a DC vem trabalhando com o pensamento CríticoTransformador, descrito por Lorenzetti (2008) como uma abordagem ambiental envolvendo fatores que explora o ambiente por meio da visão sistêmica incorporando outras dimensões que vão além das questões naturais. Por meio deste pensamento é possível proporcionar ao estudante uma percepção globalizante sobre o meio ambiente, ou seja, é possível estabelecer uma perspectiva crítica, ética e democrática sobre local onde ele vive.

Neste sentido é possível afirmar que DC procura desenvolver nos estudantes, habilidades que os estabelecem como cidadãos críticos e transformadores. De acordo com Torres (2010), esse sujeito é formado para atuar dentro da sua realidade a fim de transformá-la, tem consciência das relações existentes entre os diferentes pilares que constroem uma sociedade, porque se reconhece como parte de uma totalidade e sabe que suas ações podem proporcionar transformações dentro destas dimensões.

$\mathrm{Na}$ questão da obtenção de novos conhecimentos pelos responsáveis legais em relação a GRD, os mesmos afirmaram que aprenderam com os seus filhos, fatores para perceber e distinguir um desastre, obtenção de conhecimentos para a construção de moradias seguras, do impacto das ações das pessoas em suas comunidades e de técnicas como primeiros socorros e gestão de lixo (Quadro 5). Conforme apresentado nesta pesquisa existem na educação ambiental três macrotendências, sendo a conservacionista, pragmática e crítica (LAYRARGUES; LIMA 2014).

Todavia as macrotendências conservacionista e pragmática, apresentam baixa importância nas capacitações sobre a GRD. De acordo com Layrargues e Lima (2014) a pragmática percebe o meio ambiente destituído de componentes humanos. Isso compromete a GRD que leva em consideração aspectos como a vulnerabilidade e a exposição, além de fatores intimamente correlacionadas com os seres humanos. A vulnerabilidade dos povos é representada (1) quando as pessoas ocupam localidades que 
não são adequados para habitação; (2) quando existe a construção de edificações muito precárias e (3) quando não há condições econômicas que permitam atender às necessidades humanas (WILCHES-CHAUX, 1993).

No aspecto da macrotendência conservacionista, o foco basicamente está na ecologia, ou seja, na valorização da dimensão afetiva em relação à natureza (LAYRARGUES; LIMA, 2014). Para a capacitação de estudantes na GRD essa macrotendência também apresenta limitações. Não adianta apenas incentivar que os alunos plantem árvores para auxiliar na prevenção de deslizamentos, se não for realizada uma capacitação para que os estudantes interajam com as dimensões, aspectos geográficos, climáticos, culturais, económicos e sociais. O impacto causado pela ação ecológica será relativamente pequeno perante as demais possibilidades que podem ser exploradas na região, entre elas, representar aos estudantes por quais motivos a localidade na qual está sendo realizado o plantio da arvore é considerada vulnerável.

Por isso os mediadores da DC ao promoverem que os estudantes repassem aos seus responsáveis conhecimentos sobre a percepção de risco, os quais conseguem abstrair essas informações do ambiente, evidenciada no quadro 5, revela que a macrotendência crítica é presente no projeto e vem envolvendo aspectos como a emancipação do estudante, e a possibilidade do educando auxiliar no processo de gestão ambiental. Apresentar ênfase nesta revisão crítica fortalece fundamentos que proporcionam o enfrentamento político das desigualdades e da injustiça socioambiental (LAYRARGUES; LIMA, 2014). Fatores que são determinantes na compreensão das ações de prevenção, mitigação e preparação aos riscos de desastres.

Quadro 5: Você aprendeu alguma coisa que não sabia, através do seu filho(a)?

\begin{tabular}{|c|c|}
\hline Ideia Central - 1 & Discurso do sujeito Coletivo - 1 \\
\hline $\begin{array}{l}\text { Fatores importantes para a } \\
\text { percepção do risco de } \\
\text { desastre }\end{array}$ & $\begin{array}{l}\text { Aprendi como conhecer e perceber uma situação de risco. Observando alguma rachadura em um morro ou } \\
\text { em uma casa. Quando chove muito temos que ter cuidado com as rachaduras do solo e infiltrações, pois } \\
\text { irão causar deslizamentos. Quando observamos a inclinação das árvores próxima a casa podemos ver se o } \\
\text { solo está cedendo. Aprendi também sobre as áreas de risco e sobre o nível de rios e de barragens. }\end{array}$ \\
\hline Ideia Central - 2 & Discurso do sujeito Coletivo - 2 \\
\hline $\begin{array}{l}\text { Distinguir um desastre } \\
\text { natural }\end{array}$ & $\begin{array}{l}\text { Eu aprendi que muitos dos eventos não são necessariamente desastres naturais, mas provocados por nós } \\
\text { mesmos por meio do descarte errado do lixo ou de uma construção malfeita. O estudante reforçou o que já } \\
\text { sabíamos. Pois acompanhamos pelos meios de comunicação. Mas as informações sobre os assuntos } \\
\text { pertinentes foram novidades. Por exemplo, sempre quando está chovendo tomar cuidado com trovoada, } \\
\text { enchente e deslizamento. }\end{array}$ \\
\hline Ideia Central - 3 & Discur \\
\hline $\begin{array}{l}\text { Conhecimentos básicos para } \\
\text { a construção segura de } \\
\text { moradias }\end{array}$ & $\begin{array}{l}\text { Não podemos iniciar uma construção sem ter a autorização da prefeitura. Rachadura em um morro ou em } \\
\text { uma casa tem que chamar a Defesa Civil. Existem riscos em morar em lugares assim. Aprendi sobre os } \\
\text { cuidados que devemos ter em nossa residência. }\end{array}$ \\
\hline Ideia Central - 4 & Discurso do sujeito Coletivo - 4 \\
\hline
\end{tabular}




\begin{tabular}{|c|c|}
\hline $\begin{array}{l}\text { A importância das ações das } \\
\text { pessoas perante a } \\
\text { comunidade }\end{array}$ & $\begin{array}{l}\text { O cuidado com o meio ambiente é fundamental para uma vida melhor. Todos nós somos responsáveis } \\
\text { sobre seus atos. Precisamos trabalhar com a comunidade no sentido de aprender a prevenir, por meio da } \\
\text { conscientização e valorizar as atitudes individuais no favorecimento dos resultados coletivos. }\end{array}$ \\
\hline $\begin{array}{c}\text { Ideia Central - 5 } \\
\begin{array}{l}\text { Conhecimentos gerais sobre } \\
\text { primeiros socorros, gestão } \\
\text { do lixo, abrigos e simulações }\end{array}\end{array}$ & $\begin{array}{l}\text { Aprendi sobre a separação dos lixos recicláveis, primeiros socorros e simulações de desastre. Aprendi } \\
\text { também que a cidade conta com abrigos organizados, prontos para serem acionados, se necessários. }\end{array}$ \\
\hline
\end{tabular}

Fonte: Os autores (2019)

Na questão três, que aborda sobre a mudança no comportamento do agente mirim, os responsáveis legais afirmaram que após vivenciar as experiências propostas pela DC os estudantes apresentaram além do desenvolvimento da percepção sobre desastres, conhecimentos referentes a conservação do ambiente, melhora no envolvimento com a sua comunidade e uma mudança nas atitudes dos estudantes.

No DSC obtido da ideia central 2 que apresenta os conhecimentos sobre a conservação ambiental, confirma-se que Defesa Civil vem estimulando práticas de uma EA, que de acordo Tavolaro (2005), apresenta dentro dos sistemas naturais às principais cadeias de ação e às suas redes de poder envolvidas durante os processos de tomada de decisão. Observar-se que os alunos compreendem as conexões existentes entre os elementos do meio ambiente. Conseguem identificar que as alterações realizadas pelos humanos de maneira indevida causam perturbações severas e apresentam soluções para a problemática local (Quadro 6).

Quadro 6: Você percebeu no Agente Mirim mudança no seu comportamento ou em suas práticas diárias a partir da sua participação no Projeto Agente Mirim de Defesa Civil?

\begin{tabular}{|c|c|}
\hline Ideia Central - 1 & Discurso do sujeito Coletivo - 1 \\
\hline $\begin{array}{l}\text { Desenvolvimento de } \\
\text { percepção ambiental } \\
\text { sobre riscos de } \\
\text { desastres }\end{array}$ & $\begin{array}{l}\text { Melhorou a percepção de riscos nas situações em geral. Principalmente na identificação das áreas de risco. Houve } \\
\text { muita mudança, pois agora ele observa as rachaduras e os desmatamentos nas encostas. Quando passamos por } \\
\text { áreas de risco ele sempre comenta. Fica mais atento as construções que vê. Tem preocupação quando há uma } \\
\text { grande quantidade de chuva. Procura observar o nosso terreno e dos vizinhos e orientar quando há alguma ação } \\
\text { que possa apresentar risco para eles. Conforme alguns fatos eram vistos na rua ou na TV, ele nos dizia o que pode } \\
\text { ter causado aquele evento. Além disso, comentou sobre a importância de lembrar de levar o animal de } \\
\text { estimação, no caso das pessoas que tiverem que sair de suas casas. }\end{array}$ \\
\hline Ideia Central - 2 & Discurso do sujeito Coletivo - 2 \\
\hline $\begin{array}{l}\text { Conhecimentos sobre } \\
\text { a conservação do } \\
\text { meio ambiente }\end{array}$ & $\begin{array}{l}\text { Começou a observar o ambiente onde vive de forma diferente, prestando atenção ao aprendido. Apresentando } \\
\text { várias mudanças em como lidar com o meio ambiente e a comunidade. Percebi uma atitude positiva como ter } \\
\text { vontade de mostrar para nós pais a importância de ter um meio ambiente limpo. Está muito mais atento a } \\
\text { conservação do meio ambiente. Percebendo situações que podem acarretar um desastre, desde um simples lixo } \\
\text { descartado em lugar impróprio até um desmatamento. Assim foi possível observar no estudante um interesse } \\
\text { maior e um cuidado com que está acontecendo ao seu redor. Apresentando atitudes como juntar todo o lixo que } \\
\text { encontrava jogado na rua. }\end{array}$ \\
\hline Ideia Central - 3 & Discurso do sujeito Coletivo - 3 \\
\hline $\begin{array}{l}\text { Envolvimento com a } \\
\text { comunidade escolar }\end{array}$ & $\begin{array}{l}\text { Ficou mais consciente dos riscos envolvidos em nossa comunidade. Apresentando preocupação com o próximo. } 0 \\
\text { estudante ficou mais responsável e preocupado com as pessoas e com a cidade. Desenvolveu um olhar mais } \\
\text { crítico no comportamento das pessoas e na importância da conscientização da comunidade. Assim, enfatizou } \\
\text { sobre a importância de ouvir os alertas pelo rádio e dos vizinhos se comunicarem, pois alguém pode não ter } \\
\text { ouvido o alerta. }\end{array}$ \\
\hline Ideia Central - 4 & Discurso do sujeito Coletivo - 4 \\
\hline $\begin{array}{l}\text { Mudança nas } \\
\text { atitudes do estudante }\end{array}$ & $\begin{array}{l}\text { Ficava muito ansioso para participar das aulas e aprender algo novo. Agora tem maior atenção com as coisas que } \\
\text { vai fazer. Nos deveres de escola e tarefas domésticas. Também ficou mais calmo, pois pensa mais antes de fazer } \\
\text { qualquer coisa. Como em utilizar os conhecimentos de primeiros socorros, em caso de emergência. }\end{array}$ \\
\hline
\end{tabular}


Fonte: Os autores (2019)

Nesta pesquisa procurou-se verificar se o responsável legal observou um novo "olhar" dos agentes mirins perante a sua comunidade. De acordo com o quadro 7, ficou evidente nas três escolas analisadas que o estudante observa e percebe a importância que a sua comunidade tem na redução dos riscos, por isso se sente responsável em ajudá-la a compreender melhor os mecanismos para minimizar os desastres. De acordo com Loureiro (2005) correlacionar os problemas ambientais com o contexto social do qual os estudantes estão inseridos, são pontos que auxiliam na construção de uma consciência crítica da sociedade e das suas relações com os demais elementos do ambiente.

Quadro 7: Você observou nele um novo "olhar" para a sua comunidade"?

\begin{tabular}{|c|c|}
\hline Ideia Central - 1 & Discurso do sujeito Coletivo - 1 \\
\hline $\begin{array}{l}\text { Observa a comunidade } \\
\text { como um todo e se } \\
\text { sente responsável em } \\
\text { ajudá-la. }\end{array}$ & $\begin{array}{l}\text { Ele falava sempre sobre como ajudar a comunidade e o meio ambiente. Se preocupa com tudo, com as } \\
\text { pessoas que moram em área de risco. Apresenta um olhar para o que é certo e errado, o ruim e o bom, para a } \\
\text { comunidade. Sempre disposto em ajudar, ele pensa no entorno, observa o que está acontecendo e se alguém } \\
\text { precisa de ajuda. Têm preocupação em orientar os vizinhos quanto aos perigos de algumas ações. Assim, } \\
\text { passou a observar detalhes na vizinhança. Fica observando o comportamento das pessoas. Está mais } \\
\text { preocupado na proteção e também na possibilidade de abrigar as pessoas atingidas pelas } \\
\text { enchentes/alagamentos. Além da preocupação com o próximo, percebi que o projeto despertou nele o } \\
\text { interesse em ajudar mais e repassar o que apreendeu. Aliais, o estudante não tinha ideia de que as pessoas } \\
\text { podiam perder tanto tão rapidamente e depois podiam demorar até anos para recuperar o que tinham. Agora } \\
\text { o agente mirim vê a cidade e a comunidade com um olhar mais ampliado, mais crítico, mais preocupado com } \\
\text { as questões coletivas e mais solidário. }\end{array}$ \\
\hline Ideia Central - 2 & Discurso do sujeito Coletivo - 2 \\
\hline $\begin{array}{l}\text { Apresentou } \\
\text { conhecimentos que } \\
\text { buscam manter o meio } \\
\text { ambiente equilibrado }\end{array}$ & $\begin{array}{l}\text { Obteve um olhar mais responsável. Com muita preocupação em querer fazer as coisas. Chamou a atenção de } \\
\text { nós no sentido de não jogarmos lixos em lugares inadequados e que os vizinhos também não deveriam jogar. } \\
\text { Comentou sobre os cuidados e destinação adequada do lixo, para manter os locais comuns limpos. Reforçou } \\
\text { quanto aos cuidados e preservação do ambiente onde vive e de como se prevenir de alguma tragédia. }\end{array}$ \\
\hline Ideia Central - 3 & Discurso do sujeito Coletivo - 3 \\
\hline $\begin{array}{l}\text { Demostrou } \quad \text { maior } \\
\text { preocupação com áreas } \\
\text { de risco }\end{array}$ & $\begin{array}{l}\text { Apresenta um olhar mais atento para as coisas que acontecem, principalmente na época das chuvas. Sempre } \\
\text { fala de deslizamentos. Se preocupa com as áreas consideradas de risco em dias de chuva abundante. Observa } \\
\text { os tipos de construções, quando tem casas construídas em barrancos. }\end{array}$ \\
\hline
\end{tabular}

Fonte: Os autores (2019)

Neste discurso do sujeito coletivo é averiguado que o estudante desenvolve um olhar minucioso para pontos específicos da sua comunidade, que possibilitam identificar possíveis riscos futuros de desastres. Conforme evidenciado por Lorenzetti (2008) não basta apenas sensibilizar os alunos sobre os problemas ambientais e suas consequências para os seres vivos. No projeto AMDC os impactos negativos causados ao meio ambiente são abordados nos encontros por meio das alterações observadas nas interações entre fatores ecológicos, econômicos, sociais e culturais. Essas alterações são amplamente enfatizadas aos alunos pelos técnicos de diferentes áreas de conhecimento agregadas a atividades realizadas por meio de visitas de estudos, atividades práticas e aulas teóricas. 
Neste estudo obteve-se também a opinião dos responsáveis legais sobre o impacto do projeto perante os estudantes. Verifica-se pelos DSCs que a DC ao empregar as diferentes metodologias de ensino, descritas anteriormente, possibilita aos jovens observar os desastres em suas múltiplas dimensões, saindo da exclusividade natural e envolvendo outras esferas presentes na gestão (Quadro 8). Desta forma, os alunos compreendem que um desastre é consolidado pela união e relação entre diferentes fatores. Embasados por esses conhecimentos os agentes mirins ao concluírem seus estudos têm o poder para interagir de forma a contribuir com a transformação da sua comunidade.

Isso acontece porque o órgão de Blumenau apresenta critérios relevantes da EA crítica durante os encontros. A DC segue os princípios abordados por Loureiro (2005) que procura desenvolver a construção de conhecimentos por meio do diálogo e pelo confrontamento de ideias e posicionamentos, estimulando novas formas de constituir relações com a natureza, seguindo iniciativas que atuam sob a perspectiva da transformação social e da emancipação dos discentes. Assim os responsáveis legais esclarecem que os estudantes ao participarem dos encontros, obtêm uma transformação de percepção, descrevendo-os como cidadãos conscientes que promovem maior segurança a sua comunidade, por compreenderem a dinamismo dos riscos de desastres (Quadro 8).

Quadro 8: Qual a sua opinião sobre o Projeto de Prevenção nas escolas?

\begin{tabular}{|c|c|}
\hline Ideia Central - 1 & Discurso do sujeito Coletivo - 1 \\
\hline $\begin{array}{l}\text { Possibilita aos jovens a } \\
\text { ter uma visão } \\
\text { diferenciada sobre os } \\
\text { desastres }\end{array}$ & $\begin{array}{l}\text { Acho de suma importância projetos desse segmento nas escolas, pois traz para os alunos a devida } \\
\text { preocupação com a natureza e com o próximo. Aprendizagem que serve como forma de conscientização para } \\
\text { a percepção e prevenção de riscos. Assim, os alunos aprendem desde pequenos como se comportarem em } \\
\text { momentos de risco. O projeto está incentivando meu filho a praticar coisas boas sempre. Ensinar a ele a ter } \\
\text { mais prevenção. Aprenderem melhor sobre os desastres, como se protegerem e desde cedo a respeitar a } \\
\text { natureza para evitar os riscos. O projeto é muito educacional, que preza ensinar os participantes a como ter } \\
\text { uma visão mais ampla. É sabido que não é possível evitar todos os desastres pelo menos os naturais, mas a } \\
\text { educação pode ajudar a salvar vidas e minimizar os danos. }\end{array}$ \\
\hline Ideia Central - 2 & Discurso do sujeito Coletivo - 2 \\
\hline $\begin{array}{l}\text { Transforma os alunos } \\
\text { em verdadeiros cidadãos } \\
\text { conscientes, dando } \\
\text { maior segurança a sua } \\
\text { comunidade }\end{array}$ & $\begin{array}{l}\text { É excelente pois os nossos jovens passam as informações a comunidade. Beneficiou o meu filho em } \\
\text { informações. Ele se acha inserido na sociedade desde criança. Isso só tem a contribuir com o futuro das } \\
\text { escolas. Transformando-os em verdadeiros cidadãos conscientes. Muito boas essas iniciativas para fazer uma } \\
\text { comunidade mais segura para todos. Pois conscientiza as crianças e consequentemente os adultos sobre a } \\
\text { importância e a responsabilidade que cabe a cada um de nós. Na minha opinião é de extrema importância } \\
\text { porque desenvolve o espírito de ajuda, alerta e o solidário das crianças. Acho bastante válido qualquer esforço } \\
\text { no sentido de ajudar a dar mais segurança as comunidades. Considero muito importante, pois desperta o } \\
\text { interesse nas crianças e os motiva a ser futuramente um agente da Defesa Civil. }\end{array}$ \\
\hline Ideia Central - 3 & Discurso do sujeito Coletivo - 3 \\
\hline $\begin{array}{l}\text { O projeto deveria ser } \\
\text { ampliado, envolvendo } \\
\text { turmas de diferentes } \\
\text { anos }\end{array}$ & $\begin{array}{l}\text { Foi muito bom e poderia ter novamente. Deveria ter uma continuidade e ser um projeto permanente nas } \\
\text { escolas, uma turma em todas as unidades escolares. Acho que deveria até virar matéria obrigatória na rede de } \\
\text { ensino. Inclusive deveria ser mais intensificado, ser aplicado aos alunos mais maduros (7ㅇ, 8ㅇ e 9o anos) ou se } \\
\text { pensar em estender para os alunos menores, porém de uma forma lúdica. }\end{array}$ \\
\hline
\end{tabular}
Fonte: Os autores (2019) 
Por fim, questionado se os responsáveis tinham considerações, sugestões ou reclamações sobre o projeto desenvolvido no município, em primeiro lugar foi colocado que o AMDC tem grande relevância para a comunidade escolar, mas que necessita ter uma expansão para as demais escolas de Blumenau, assim como da sua vinculação na grade escolar. Também aparece no discurso uma colocação interessante, enfatizando que exista um encontro que possa reunir todos os agentes mirins e que esses alunos também obtenham novas atribuições como ter a possibilidade de capacitar estudantes menores (Quadro 9). Este levantamento é interessante, pois conforme evidenciado por Narváez, Lavell e Ortega (2009) a gestão de desastre não está relacionada apenas em um projeto com um produto determinado, mas sim na aplicação contínua de princípios e ações voltados para a gestão. Vale reforçar que o projeto AMDC visa fazer com que os agentes mirins continuem atuando perante a sua comunidade e tornem-se disseminadores destas informações.

Quadro 9: Caso desejares, comente suas considerações, sugestões ou reclamações sobre o projeto Agente Mirim de Defesa Civil?

\begin{tabular}{|c|c|}
\hline Ideia Central - 1 & Discurso do sujeito Coletivo - 1 \\
\hline $\begin{array}{l}\text { Projeto de grande relevância } \\
\text { para a comunidade escolar }\end{array}$ & $\begin{array}{l}\text { Eu considero um programa maravilhoso para ajudar as crianças da sociedade. Acho que deviam ser } \\
\text { mantidos por mais tempo nas escolas. Considero o AMDC um dos melhores projetos que o meu filho } \\
\text { participou. Ótima iniciativa que não pode parar. Desejo que tenham outras iniciativas como essa, pois } \\
\text { fazem muito bem para que nossas crianças cresçam muito mais como pessoa. Sempre bom um projeto } \\
\text { no qual se vê resultado, gostamos muito, só tem a contribuir positivamente nas nossas crianças e na } \\
\text { sociedade. Dando oportunidades para as crianças terem conhecimento direto sobre os assuntos } \\
\text { vivenciados em experiências únicas. }\end{array}$ \\
\hline Ideia Central - 2 & Discurso do sujeito Coletivo - 2 \\
\hline $\begin{array}{l}\text { Expansão do projeto com sua } \\
\text { inclusão nas demais escolas do } \\
\text { município }\end{array}$ & $\begin{array}{l}\text { Sugiro que esse projeto se expanda para mais crianças e gere ainda mais conhecimento para prevenir } \\
\text { desastres naturais. Deveria ser incorporado como disciplina na grade curricular, se expandir para todas } \\
\text { as escolas ou talvez estar como uma disciplina extraclasse para ter uma continuidade. Bom seria que } \\
\text { mais turmas participassem do projeto no ano. Aliais, também deveria continuar sendo realizado na } \\
\text { nossa unidade escolar principalmente porque vivemos em uma região com frequente situação de risco } \\
\text { ou desastres ambientais. E como sugestão não cancelar as visitas em função das chuvas, explorar o mau } \\
\text { tempo para conscientização/prática. }\end{array}$ \\
\hline Ideia Central - 3 & Discurso do sujeito Coletivo - 3 \\
\hline $\begin{array}{l}\text { Proposta para que os alunos } \\
\text { formados possam se reunir e } \\
\text { ter a atribuição de repassar } \\
\text { seus conhecimentos aos } \\
\text { alunos de outras séries }\end{array}$ & $\begin{array}{l}\text { Seria muito importante que uma vez por ano reunissem todo os agentes mirins da escola durante um } \\
\text { dia, para incentivá-los a colocarem em prática tudo o que eles aprenderam, mas de um modo concreto } \\
\text { (Ação). Acredito que as crianças são impactadas por todos esses aprendizados e serão multiplicadoras } \\
\text { dessa formação. Por isso, sugiro que mais para frente os agentes mirins formados possam passar seus } \\
\text { conhecimentos para os alunos das séries iniciais. }\end{array}$ \\
\hline
\end{tabular}
Fonte: Os autores (2019)

Portanto a Defesa Civil de Blumenau ao abordar o pensamento ambientalista CríticoTransformador, conforme discutido por Tavolaro (2005), Lorenzetti (2008) e Torres (2010), têm um grande potencial para sensibilizar a população local sobre os desastres, visto que nessa abordagem é possível trabalhar com um modelo sistêmico do ambiente. Para GRD é imprescindível aplicar e avaliar diferentes dimensões, além do aspecto natural, pois quando o mediador fica restrito apenas a este caráter pode desenvolver no estudante uma visão 
fragmentada do sistema, dificultando a compreensão da problemática ambiental (LORENZETTI, 2008). Especialmente se o estudante não conseguir observar seu papel. Fragilizando totalmente a questão da compreensão dos processos da GRD que incorpora os seres vivos e suas relações com o ambiente.

Na concepção educacional freireana, a separação entre sujeito e objeto torna-se inviável, uma vez que não existem homens sem mundo e nem mundo sem homens, pois os homens são corpos conscientes no mundo e o mundo existe porque os homens são corpos conscientes (a consciência da consciência de) (TORRES, 2010 p. 165).

Desta forma, para que as ações de gestão sejam efetivas na prática pela comunidade, torna-se necessário que se estabeleça uma cultura de gestão de risco por parte de todos os envolvidos nesse processo, enfatizando principalmente as comunidades que são mais suscetíveis a danos e prejuízos (SILVEIRA; CARDOSO, 2016). Salienta-se nesta pesquisa que este aspecto vem ocorrendo na execução do AMDC, pois o projeto busca principalmente trabalhar com comunidades escolares que estão localizadas em áreas vulneráveis fazendo com que os estudantes compreendam seu papel dentro deste sistema.

Conforme observado na análise dos questionários é possível preparar as comunidades vulneráveis para o enfrentamento de desastres. Neste estudo foi possível confirmar que a capacitação abrangeu as escolas e seu contexto familiar. $\mathrm{O}$ aluno tornou-se um multiplicador, expandindo o conhecimento além da classe. Esta evidência é corroborada pelos responsáveis legais, os quais apresentaram conhecimentos notáveis sobre GRD que podem ser empregados antes, durante e após um desastre. Apesar do reduzido número de agentes mirins participantes por área e ano, em média de 30 estudantes, houve um significativo impacto desta ação junto às comunidades, desde sua implementação. Até o ano de 2019 participaram 210 estudantes das escolas municipais e estaduais. Destes, se cada estudante tiver dois responsáveis legais o número pode chegar a 630 indivíduos impactados diretamente pelo projeto. Somado a isso há os impactados indiretamente, portanto, o valor apresentado pode aumentar consideravelmente.

Como o intuito do AMDC é continuar expandindo pela cidade é provável que a média de participantes aumente, como ocorreu em 2019 com a inscrição de 90 alunos. Todavia, apesar de ser averiguado neste estudo a relevância que a capacitação dos estudantes 
proporciona, as formas tradicionais da gestão de riscos de desastres na grande maioria dos municípios brasileiros, tendem a estar pautadas exclusivamente em ações estruturais, sendo poucas as ações não-estruturais, como os projetos educacionais, que envolvem o planejamento territorial e a educação.

De acordo com Sulaiman (2014) as primeiras experiências de EA para GRD foram realizadas em espaços educativos não escolares. Além disso, a abordagem dos riscos e desastres naturais se apoiou principalmente na educação informal, especialmente em processos e materiais de comunicação, com o foco na perpetuação e disponibilização de informações para a conscientização e mobilização social. Contudo, é relevante destacar que no Brasil a importância da educação para gestão dos riscos no ensino fundamental é uma exigência da Política Nacional de Proteção e Defesa Civil (PNPDEC), Lei $n^{\circ} 12.608$, de 10 de abril de 2012. Este aparato legal estabelece ações de EA nas escolas ao alterar o artigo 26 da Lei $n^{\circ}$ 9.394/96 de Diretrizes e Bases da Educação Nacional (LDB). Essa alteração feita pela PNPDEC determina que os currículos do ensino fundamental e médio devem incluir os princípios da proteção e defesa civil e a educação ambiental (BRASIL, 2012).

\section{Considerações Finais}

Com a presente pesquisa foi possível observar que o trabalho desenvolvido pela DC em Blumenau vem promovendo o resultado que era esperado pelo órgão municipal, sendo este a capacitação da população no enfrentamento dos desastres naturais. Analisando o projeto ao longo dos cinco anos é importante salientar que os resultados confirmam este fato, pois os estudantes continuam a aplicar no seu cotidiano o que aprenderam, repassando aos seus responsáveis conhecimento sobre GRD.

Por meio das análises dos dados foi possível averiguar que os responsáveis legais mantêm a percepção de risco, mesmo quando a participação dos alunos no projeto ocorreu anos atrás. Isso confirma três pontos sobre a aplicação do AMDC em Blumenau. O primeiro é que os conhecimentos mediados e construídos como os estudantes são repassados a sua comunidade, tornando-os envolvidos na capacitação como multiplicadores. O segundo ponto relaciona-se ao aspecto da passagem do tempo da aplicação do projeto. Mesmo após 
anos da sua inserção nas escolas, os responsáveis que tiveram contato com os estudantes ainda mantêm uma percepção associada a GRD. O terceiro ponto está no aspecto de como essa mediação ocorre.

Corrobora-se que a Defesa Civil de Blumenau trabalha com o pensamento CríticoTransformador. Assim, formam os estudantes para que eles consigam observar o sistema em que sua comunidade está inserida com todas suas complexidades e interações, envolvendo múltiplas esferas como a ambiental, social, ecológica, econômica, cultural e dentre outras que movimentam as engrenagens de um meio ambiente que tende a se manter equilibrado. Portanto, os estudantes se reconhecem como agentes tomadores de decisão dentro da sua comunidade. Desta forma, constroem vínculo ativo para o desenvolvimento de uma sociedade democrática e participativa.

Um ponto que deve ser observado com maiores detalhes pelo órgão público é a retroalimentação posterior do AMDC, entendendo, conforme discutido nos resultados que a GRD deve ser um processo contínuo. Faz a necessidade que órgão da DC continue interagindo com os ex-participantes, por meio de atividades após a conclusão do projeto ou procure outra estratégia para dar continuidade nesta capacitação no decorrer dos anos em que o estudante estiver na unidade. Desta forma é interessante que o órgão de Blumenau reveja sua metodologia a ser aplicada, especialmente quando a meta é trabalhar com maior número de envolvidos e com qualidade priorizando a GRD no ambiente escolar.

\section{Agradecimentos}

O presente trabalho foi realizado com apoio da Coordenação de Aperfeiçoamento de Pessoal de Nível Superior - Brasil (CAPES) - Código de Financiamento 001

\section{Referências}

AVILA, M. R. R.; MATTEDI, M. A. Desastre e território: a produção da vulnerabilidade a desastres na cidade de Blumenau/SC. URBE - Revista Brasileira de Gestão Urbana, Curitiba, v. 9, n. 2, p. 187-202, maio/ago. 2017. 
BRASIL. Lei no 12.608, de 10 de abril de 2012 - Institui a Política Nacional de Proteção e Defesa Civil - PNPDEC; dispõe sobre o Sistema Nacional de Proteção e Defesa Civil - SINPDEC e o Conselho Nacional de Proteção e Defesa Civil - CONPDEC. Diário Oficial da União, 2012.

BLUMENAU. In: GOOGLE EARTH. 2020. Disponível em: <https://earth.google.com/web/search/blumenau>. Acesso em: 17 jan.2020.

CAVALCANTI, Y. W. et al. Motivações, práticas e percepções de cirurgiões-dentistas sobre o trabalho na Atenção Básica de João Pessoa - PB. Revista da Faculdade de Odontologia da Universidade de Passo Fundo, Passo Fundo, v. 15, n. 3, p. 228-232, set./dez. 2010.

LAYRARGUES, P. P.; LIMA, G. F. D. C. As macrotendências político-pedagógicas da educação ambiental brasileira. Ambiente \& Sociedade, São Paulo, v. 17, n. 1, jan. /mar. 2014.

LEFEVRE, A. M. C.; CRESTANA, M. F.; CORNETTA, V. K. A Utilização da metodologia do discurso do sujeito coletivo na avaliação qualitativa dos cursos de especialização "capacitação e desenvolvimento de recursos humanos em saúde - CADRHU", São Paulo 2002. Saúde e Sociedade, São Paulo, v. 12, n. 2, p. 68-75, ago./dez. 2003.

LEFÈVRE, F.; LEFÈVRE, A. M. C. O discurso do sujeito coletivo: um novo enfoque em pesquisa qualitativa (desdobramentos). 2. ed. Caxias do Sul: EDUCS, 2005. 256 p.

LOCALIZAÇÃO de Blumenau em Santa Catarina. In: WIKIPÉDIA: a enciclopédia livre. [São Francisco, CA: Fundação Wikimedia], 2006. Disponível em:

<https://commons.wikimedia.org/wiki/File:SantaCatarina Municip Blumenau.svg>. Acesso em: 28 fev. 2020

LORENZETTI, L. Estilos de pensamento em educação ambiental: uma análise a partir das dissertações e teses. 2008. 407 p. Tese (Doutorado em Educação Científica e Tecnológica) Universidade Federal de Santa Catarina, Florianópolis, 2008.

LOUREIRO, C. F. B. Teoria Crítica. In: MMA - Ministério do Meio Ambiente (org.). Encontros e Caminhos: Formação de Educadoras(es) Ambientais e Coletivos Educadores. Brasilia: MMA, Diretoria de Educação Ambiental, 2005. p. 325-332.

NARVÁEZ, L.; LAVELL, A.; ORTEGA, G. P. La Gestión del Riesgo de Desastres: Un enfoque basado en procesos. 1. ed. Lima: Secretaría General de la Comunidad Andina, 2009.

OLIVEIRA, F. R. DE; OURIQUES, J. M. DE A.; CORREIA, L. S. Percepção de risco a partir do Programa Defesa Civil na Escola em Blumenau. Territorium, Vilarinho Lsa, v. 25 n. 2, p. 7992, 2018. 
ONU. Como construir cidades mais resilientes - um guia para gestores públicos locais: Uma contribuição à Campanha Global 2010-2015 - Construindo Cidades Resilientes - Minha Cidade está se preparando!, 2012. Genebra, Novembre de 2012. Disponível em: <http://www.unisdr.org/files/26462 guiagestorespublicosweb.pdf>. Acessado em: abr. 2020.

ROSA, T. D. S. et al. A educação ambiental como estratégia para a redução de riscos socioambientais. Ambiente \& Sociedade, São Paulo, v. 18, n. 3, p. 211-230, jul. /set. 2015.

SILVEIRA, M. V.; CARDOSO, C. Promoção da cultura de riscos de desastres. Revista ordem pública e defesa social, v. 9, n. 1, p. 211-222, jan./jun. 2016.

SULAIMAN, S. N. De que adianta? O papel da educação para a prevenção de desastres naturais. 2014. 289 p. Tese (Doutorado em Educação) - Faculdade de Educação, Universidade de São Paulo, São Paulo, 2014.

TAVOLARO S. B. F. Ação comunicativa In: MMA - Ministério do Meio Ambiente (org.). Encontros e Caminhos: Formação de Educadoras(es) Ambientais e Coletivos Educadores. Brasilia: MMA, Diretoria de Educação Ambiental, 2005. p. 17-25

TORRES, J.R. Educação Ambiental Crítico-Transformadora e Abordagem Temática Freireana. 2010. 456 p. Tese. (Doutorado em Educação Científica e Tecnológica) - Programa de Pós Graduação em Educação Científica e Tecnológica, Universidade Federal de Santa Catarina, Florianópolis, 2010.

UNISDR. Sendai Framework for Disaster Risk Reduction 2015-2030, 2015. Marco de Sendai para a Redução do Risco de Desastres 2015- 2030 Sendai Geneva: United Nations Office for Disaster Risk Reduction, 2015. Disponível em:

<http://www1.udesc.br/arquivos/id submenu/1398/traduzido unisdr novo sendai fram ework for disaster risk reduction 20152030 portugues versao 31mai2015.pdf>.

Acesso em: 10 fev. 2017

UNISDR. Manual para líderes de los gobiernos locales Desarrollando ciudades resilientes, i Mi ciudad se está preparando!, 2017. Disponível em:

<https://www.unisdr.org/files/26462 manualparalideresdelosgobiernosloca.pdf>. Acesso em: 12 set. 2018.

VIEIRA, R.; RIBEIRO, J. Agente Mirim de Defesa Civil: Educação ambiental para prevenção e redução de riscos de desastres naturais em Blumenau, Santa Catarina. Revista

Contrapontos, Itajaí, v. 18, n. 1, p. 68-87, jan./mar. 2018. 
WILCHES-CHAUX, G. La vulnerabilidad global. In: Maskrey, A. (org). Los desastres no son naturales. LARED, - Red de Estudios Sociales en Prevención de Desastres en América Latina, 1993. Disponível em:

$<$ https://www.desenredando.org/public/libros/1993/ldnsn/LosDesastresNoSonNaturales1.0.0.pdf $>$. Acesso em: 20 mar. 2020

Submetido em: 16-04-2020. Publicado em: 23-04-2021. 